\title{
Analisa Koefisien Harga Satuan Tenaga Kerja di Lapangan Dengan Analisa SNI Struktur Bangunan Gedung di Kota Jambi
}

\author{
Elvira Handayani, M. Nuklirullah, Ahmad Riyadi* \\ Fakultas Teknik Sipil Universitas Batanghari Jambi \\ *Correspondence email: ahmadriyadiengineer@gmail.com
}

\begin{abstract}
Abstrak. Dalam pelaksanaan suatu proyek, Penelitian yang berkaitan dengan tenaga kerja, upah, dan bahan merupakan hal penting yang perlu diperhitungkan. Pekerjaan sekecil apapun apabila tidak didukung dengan tenaga kerja yang berkemampuan kerja yang baik dan bahan yang bermutu baik, tidak akan memberikan hasil yang maksimal dan memuaskan dalam sebuah proyek. Bahkan akibat penggunaan sumber daya manusia yang kurang tepat bisa mengakibatkan kerugian yang besar pada proyek kontruksi. Karna itu perlu dilakukan penelitian terhadap koefisien satuan kerja untuk jenis pekerjaan kolom beton bertulang mengingat koefisien satuan kerja merupakan faktor yang sangat penting dalam penetapan upah kerja dan bahan sehingga diperoleh perbandingan koefisien satuan kerja yang bertujuan untuk mengetahui kesesuaiannya. Penelitian lapangan dilakukan dengan menggunakan metode "Time And Motion Study Analysis" yaitu metode yang pengambilan data lapangan dilakukan dengan cara melakukan pengamatan proses pelaksanaan dilapangan dengan mencatat lamanya gerak kerja dari pekerja dalam menyelesaikan satu jenis pekerjaan. Observasi di lapangan adalah mengenai produktivitas pekerja pada pekerjaan struktur beton yang terdiri dari pekerjaan pemasangan bekisting, pekerjaan pembesian, dan pekerjaan pengecoran. Pekerjaan struktur yang di amati hanyalah pekerjaan kolom. Pada saat dilapangan peralatan yang digunakan untuk menghitung waktu lama pekerjaan adalah menggunakan stopwatch. Perhitungan ini dilakukan dengan melakukan studi kasus pada Pekerjaan Rehab Berat Gedung Utama Korem kota Jambi. Dari data pengamatan di lapangan dan analisa perhitungan maka diperoleh koefisien satuan kerja untuk pekerjaan kolom ukuran 40x40 cm lantai 1 yaitu pada pekerjaan $10 \mathrm{~kg}$ pembesian, pekerja sebesar 0.0630 , tukang besi sebesar 0.0610, mandor sebesar 0.0400. Pada pekerjaan $1 \mathrm{~m}^{2}$ bekisting, pekerja sebesar 0.5200, tukang kayu sebesar 0.0323 , mandor sebesar 0.0280. Pada pekerjaan $1 \mathrm{~m}^{3}$ pengecoran beton, tukang batu sebesar 0.1190, mandor sebesar 0.0714.
\end{abstract}

Kata Kunci: Koefisien Satuan Tenaga Kerja, Time And Motion Study

\section{PENDAHULUAN}

Kegiatan Proyek dapat diartikan sebagai kegiatan sementara yang berlangsung dalam jangka waktu terbatas, dengan alokasi sumber daya tertentu dan dimaksud untuk menghasilkan produk atau deliverable yang kriteria mutunya tetap digariskan dengan jelas (Soeharto, 1997). Sumber daya yang dimaksud adalah manusia (tenaga kerja), material peralatan dan modal (ataupun) biaya. Faktor penentu suatu proyek adalah tenaga kerja.

Analisa harga satuan pekerjaan adalah suatu cara perhitungan harga satuan pekerjaan kosntruksi yang dijabarkan dalam perkalian kebutuhan bahan bangunan, upah kerja, dan peralatan dengan harga bangunan standar pengupahan untuk menyelesaikan persatuan pekerjaan konstruksi (Ibrahim, 1993).

Di dalam menganalisa harga satuan upah kerja digunakan suatu metode yaitu metode SNI (Standar Nasional Indonesia). Prinsip mendasar pada metode SNI adalah daftar koefisien bahan, upah kerja dan alat sudah ditetapkan. Sedangkan dalam menganalisa upah berdasarkan produktivitas digunakan metode pengamatan langsung. Metode ini digunakan untuk mengetahui kondisi yang sebenarnya terjadi di lapangan.

Berdasarkan latar belakang permasalahan tersebut perlu dilakukan analisa perbandingan harga upah kerja dengan metode SNI dan upah kerja berdasarkan produktivitas kerja diharapkan dapat digunakan dalam estimasi upah kerja pada suau proyek konstruksi. Dengan diketahuinya perbandingan biaya upah tersebut maka akan membantu perusahaan sebagai bahan pertimbangan dalam perencanaan biaya upah kerja.

\section{METODE}

Pengumpulan data ini diperoleh dari survey langsung di lapangan dan dari instansi terkait. Data-data yang dimaksudkan adalah data primer dan data sekunder sebagai berikut :

1. Data Primer

a. Jumlah tenaga kerja persatuan pekerjaan

b. Upah realisasi harian

2. Data Sekunder

a. Gambar Kerja

b. Analisa Harga Satuan Pekerjaan 
Elvira Handayani, M. Nuklirullah dan Ahmad Riyadi, Analisa Koefisien Harga Satuan Tenaga Kerja di Lapangan Dengan Analisa SNI Struktur Bangunan Gedung di Kota Jambi

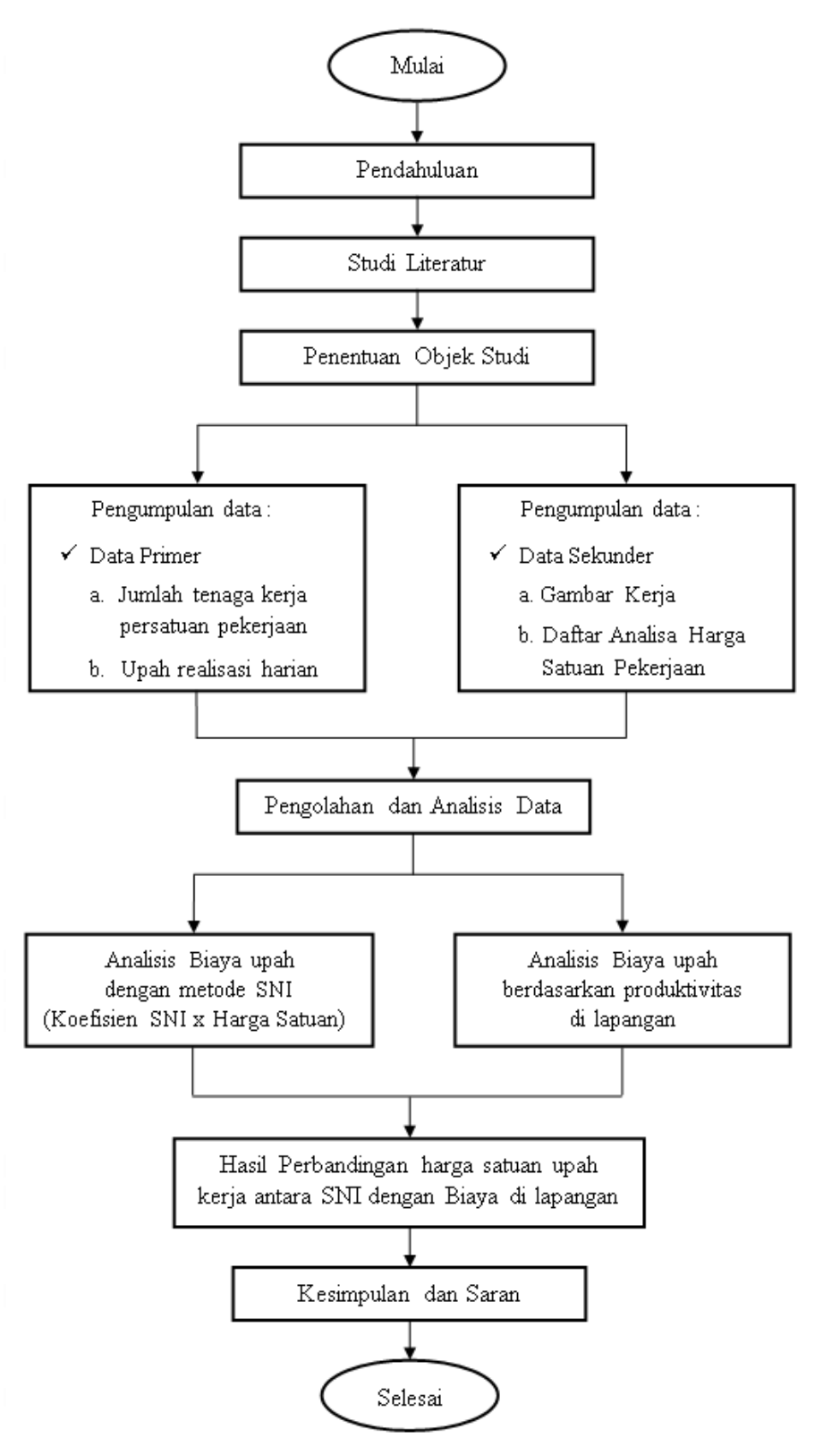

Sumber: Hasil Analisa, 2018

Gambar 1. Bagan Alir Penelitian

\section{HASIL DAN PEMBAHASAN}

\section{Objek Penelitian}

Pada bab ini akan dijelaskan mengenai hasil pengamatan langsung di lapangan tentang perhitungan harga satuan pekerjaan Kolom Beton Bertulang dengan menggunakan pengamatan langsung di lapangan dan analisa SNI. Perhitungan ini dilakukan dengan melakukan studi kasus pada Pekerjaan Rehab Berat Gedung Utama Korem kota Jambi.

\section{Perhitungan Koefisien Pekerja}

Data Primer

Berikut data yang diperoleh dilapangan: Lantai 1

Tabel 1. Data hasil pengamatan untuk menyelesaikan 1 pembesian kolom

\begin{tabular}{|c|c|c|c|}
\hline No. & Tenaga Kerja & Kebutuhan & Lamanya pengerjaan (jam) / hari \\
\hline 1. & Pekerja & 4 Orang & \\
\hline 2. & Tukang Besi & 2 Orang & 7 jam \\
\hline 3. & Mandor & 1 Orang & \\
\hline
\end{tabular}

Sumber: Hasil Pengamatan Lapangan, 2018 
Elvira Handayani, M. Nuklirullah dan Ahmad Riyadi, Analisa Koefisien Harga Satuan Tenaga Kerja di Lapangan Dengan Analisa SNI Struktur Bangunan Gedung di Kota Jambi

Tabel 2. Data hasil pengamatan untuk menyelesaikan 1 bekisting kolom

\begin{tabular}{clcc}
\hline No. & \multicolumn{1}{c}{ Tenaga kerja } & Kebutuhan & Lamanya pengerjaan (jam) / hari \\
\hline 1. & Pekerja & 3 Orang & 7 jam \\
2. & Tukang Kayu & 2 Orang & \\
3. & Mandor & 1 Orang & \\
\hline
\end{tabular}

Sumber: Hasil Pengamatan Lapangan, 2018

Tabel 3. Data hasil pengamatan untuk menyelesaikan pengecoran kolom

\begin{tabular}{cccc}
\hline No. & Tenaga Kerja & Kebutuhan & Lamanya pengerjaan (jam) / hari \\
\hline 1. & \multirow{2}{*}{ Tukang Batu Mandor } & 4 Orang & 7 jam \\
\hline
\end{tabular}

Sumber: Hasil Pengamatan Lapangan, 2018

\section{Metode Pengamatan}

Time Study atau pembelajaran waktu adalah metode pengukuran produktivitas dari tenaga kerja di lapangan dengan cara menentukan waktu standar untuk suatu pekerjaan. Produktivitas Tenaga Kerja adalah kemampuan tenaga kerja dalam berproduksi dibandingkan dengan input yang digunakan. Seseorang dikatakan produktif apabila mampu menghasilkan barang/jasa sesuai dengan yang di harapkan dalam waktu yang singkat dan tepat.

Pengukuran Produktivitas Tenaga Kerja sebagai sarana untuk menganalisa dan mendorong efisiensi produksi suatu pekerjaan. Manfaat lain adalah untuk menentukan target dan kegunaan, praktisnya sebagai standar pemberian upah.

Observasi di lapangan adalah mengenai produktivitas pekerja pada pekerjaan struktur beton yang terdiri dari pekerjaan pemasangan bekisting, pekerjaan pemasangan penulangan, dan pekerjaan pengecoran. Pekerjaan struktur yang di amati hanyalah pekerjaan kolom. Pada saat dilapangan peralatan yang digunakan untuk menghitung waktu lama pekerjaan adalah menggunakan stopwatch. Berikut adalah pembahasan mengenai pekerjaan struktur beton bertulang pada Pekerjaan Rehab Berat Gedung Utama Korem kota Jambi.

\section{Perhitungan Koefisien Tenaga Kerja}

Perhitungan koefisien tenaga kerja dapat dilakukan setelah diperoleh nilai dari lama waktu pengerjaan jenis pekerjaan yang telah ditetapkan dari hasil survey lapangan. Pada penelitian ini jenis pekerjaan yang diteliti adalah pekerjaan kolom beton bertulang. Lokasi proyek yang di tinjau adalah lokasi Pekerjaan Rehab Berat Gedung Utama Korem. Adapun perhitungan indeks satuan kerja dari penelitian ini adalah:

\section{Koefisien Tenaga kerja di Lapangan untuk Pekerjaan Kolom Beton Bertulang Pekerjaan Pembesian}

- Tukang besi

Pekerjaan Pembesian yang dilakukan oleh 1 orang tukang besi dapat merakit besi sebesar 52,45 $\mathrm{kg}$ dalam waktu 134 menit waktu bersih menggunakan stopwatch pada saat perakitan tulangan

Time Factor ditentukan untuk mengetahui besarnya indeks waktu produktif tenaga kerja. Besarnya Time Factor dihitung dengan persamaan berikut:

$\begin{aligned} \text { Time Factor } & =\frac{\text { Waktu Produltif }}{\text { Total Waltu yang disediakar }} \\ & =\frac{134 \text { menit }}{60 \text { menit }}=2,2333 \text { jam tenaga kerja }\end{aligned}$

Maka man hour untuk $1 \mathrm{~kg}$ volume besi adalah $=\frac{2,2333 \mathrm{jam}}{52,45 \mathrm{~kg}}=0,0426 \mathrm{jam} / \mathrm{kg}$

Maka Indeks Man day untuk $1 \mathrm{~kg}$ volume besi adalah:

Man day (koefisien) $\quad=\frac{\text { Koefisien. Man How }}{\text { Jumlah jam kerja dalam } 1 \text { hari }}$

$$
=\frac{0,0426 \text { jamkg }}{\text { T jam }}=0,0061 \text { orang hari }
$$

Pada tabel analisa SNI 2016 digunakan untuk per $10 \mathrm{~kg}$ jadi koefisien Man Day di kali kan dengan $10=0,0061$ x $10=0,0610$ orang hari 
Elvira Handayani, M. Nuklirullah dan Ahmad Riyadi, Analisa Koefisien Harga Satuan Tenaga Kerja di Lapangan Dengan Analisa SNI Struktur Bangunan Gedung di Kota Jambi

Tabel 4. Koefisien indeks Man Day Untuk setiap pekerja pada pekerjaan Pembesian

\begin{tabular}{clcccc}
\hline No & Tenaga Kerja & Faktor Waktu (Time Factor) & Orang Jam (Man Hour) & Orang Hari (Man Day) & Satuan \\
\hline 1. & Pekerja & 0,5710 & 0,0439 & 0,0630 & $\mathrm{OH}$ \\
2. & Tukang Besi & 2,2333 & 0,0426 & 0,0610 & $\mathrm{OH}$ \\
3. & Mandor & 0,1667 & 0,0278 & 0,0400 & $\mathrm{OH}$ \\
\hline
\end{tabular}

Sumber: Hasil Perhitungan, 2018

\section{Pekerjaan Bekisting}

- Tukang kayu

Pekerjaan Pasangan bekisting yang dilakukan oleh 1 orang tukang kayu dapat menghasilkan volume kayu sebesar $3 \mathrm{~m}^{2}$ dalam waktu 40,65 menit.

Time Factor ditentukan untuk mengetahui besarnya indeks waktu produktif tenaga kerja. Besarnya Time Factor dihitung dengan persamaan berikut :

Time Factor

$$
\begin{aligned}
& =\frac{\text { Waktu Produltif }}{\text { Total Waltu yang disediakar }} \\
& =\frac{40,65 \text { menil }}{60 \text { menit }} \\
& =0,6775 \text { jam tenaga kerja }
\end{aligned}
$$

Maka man hour untuk $1 \mathrm{~m}^{2}$ volume kayu adalah $=\frac{0,6675 \mathrm{jam}}{3 \mathrm{~m}^{2}}=0,2258 \mathrm{jam} / \mathrm{m}^{2}$

Maka Indeks Man day untuk $1 \mathrm{~m}^{2}$ volume kayu adalah:

$$
\begin{aligned}
\text { Man day (koefisien) } \quad & =\frac{\text { Koefisian Man How }}{\text { Jumlah jam Karja dalam } 1 \text { hari }} \\
& =\frac{0,2258 \text { jamm }}{7 \text { jam }} \\
& =0,0323 \text { orang hari }
\end{aligned}
$$

Tabel 5. Koefisien indeks Man Day Untuk setiap pekerja pada pekerjaan Bekisting

\begin{tabular}{clcccc}
\hline No & Tenaga Kerja & Faktor Waktu (Time Factor) & Orang Jam (Man Hour) & Orang Hari (Man Day) & Satuan \\
\hline 1. & Pekerja & 6,8250 & 2,2750 & 0,5200 & $\mathrm{OH}$ \\
2. & Tukang Kayu & 0,6775 & 0,2258 & 0,0323 & $\mathrm{OH}$ \\
3. & Mandor & 0,5880 & 0,1960 & 0,0280 & $\mathrm{OH}$ \\
\hline
\end{tabular}

Sumber: Hasil Perhitungan, 2018

\section{Pekerjaan Pengecoran}

- Tukang Batu

Pekerjaan Pengecoran beton dilakukan dengan menggunakan site mix. pekerjaan pengecoran dilakukan oleh 1 tukang batu dengan waktu 50 menit untuk satu site mix $1 \mathrm{~m}^{3}$.

Time Factor ditentukan untuk mengetahui besarnya indeks waktu produktif tenaga kerja. Besarnya Time Factor dihitung dengan persamaan berikut:

$$
\begin{aligned}
& \text { Time Factor }=\frac{\text { Walktu Produltif }}{\text { Total Waltu yang disediakar }} \\
& =\frac{50 \text { meni1 }}{60 \text { meni1 }}=0,8333 \text { jam tenaga kerja }
\end{aligned}
$$

Maka man hour untuk $1 \mathrm{~m}^{3}$ volume pengecoran adalah:

Time Factor $=\frac{0,8333 \mathrm{jam}}{1 \mathrm{~m}^{3}}=0,8333 \mathrm{jam} / \mathrm{m}^{3}$

Maka Indeks Man day untuk $1 \mathrm{~m}^{3}$ volume coran adalah:

$$
\text { Man day (koefisien) } \quad=\frac{\text { Koefisien Man How }}{\text { Jumlah jam herja dalam } 1 \text { hari }}
$$


Elvira Handayani, M. Nuklirullah dan Ahmad Riyadi, Analisa Koefisien Harga Satuan Tenaga Kerja di Lapangan Dengan Analisa SNI Struktur Bangunan Gedung di Kota Jambi

$$
=\frac{0,8333 \text { jamm }}{\mathbb{7} \mathrm{jam}}=0,1190 \text { orang hari }
$$

Tabel 6. Koefisien indeks Man Day Untuk setiap pekerja pada pekerjaan Pengecoran

\begin{tabular}{cccccc}
\hline No & Tenaga Kerja & Faktor Waktu (Time Factor) & Orang Jam (Man Hour) & Orang Hari (Man Day) & Satuan \\
\hline 1. & Tukang Batu & 0,0833 & 0,0833 & 0,1190 & $\mathrm{OH}$ \\
2. & Mandor & 0,0500 & 0,0500 & 0,0714 & $\mathrm{OH}$ \\
\hline
\end{tabular}

Sumber: Hasil Perhitungan, 2018

Perbandingan Koefisien Tenaga Kerja di Lapangan dengan SNI 2016 Analisa Harga Satuan Pekerjaan SNI 2016

Tabel 7. Pembesian $10 \mathrm{~kg}$ dengan Besi Polos atau Besi Ulir

\begin{tabular}{|c|c|c|c|c|c|c|}
\hline No & Uraian & Kode & Satuan & Koefisien & Harga Satuan (Rp) & Jumlah Harga (Rp) \\
\hline $\mathrm{A}$ & $\begin{array}{l}\text { TENAGA } \\
\text { Pekerja } \\
\text { Tukang Besi } \\
\text { Kepala Tukang } \\
\text { Mandor }\end{array}$ & $\begin{array}{l}\text { L.01 } \\
\text { L.02 } \\
\text { L.03 } \\
\text { L.04 }\end{array}$ & $\begin{array}{l}\mathrm{OH} \\
\mathrm{OH} \\
\mathrm{OH} \\
\mathrm{OH}\end{array}$ & $\begin{array}{l}0.0700 \\
0.0700 \\
0.0700 \\
0.0700\end{array}$ & $\begin{array}{r}77,600.00 \\
93,120.00 \\
106,700.00 \\
101,850.00\end{array}$ & $\begin{array}{r}5,432.00 \\
6,518.40 \\
746.90 \\
407.40\end{array}$ \\
\hline & & & & \multicolumn{2}{|r|}{ Jumlah Harga } & $13,104.70$ \\
\hline
\end{tabular}

Sumber: SNI 2016, 2018

Tabel 8. Pemasangan $1 \mathrm{~m} 2$ Bekisting untuk Kolom

\begin{tabular}{|c|l|c|r|r|r|r|}
\hline No & Uraian & Kode & Satuan & Koefisien & Harga Satuan (Rp) & Jumlah Harga (Rp) \\
A & Tenaga & & & & & \\
& Pekerja & L.01 & OH & 0.6600 & $77,600.00$ & $51,216.00$ \\
& Tukang Kayu & L.02 & OH & 0.3300 & $93,120.00$ & $30,729.60$ \\
& Kepala Tukang & L.03 & OH & 0.0330 & $106,700.00$ & $3,521.10$ \\
& Mandor & L.04 & OH & 0.0330 & $101,850.00$ & $3,361.05$ \\
\hline \multicolumn{7}{|l|}{} \\
\hline
\end{tabular}

Sumber: SNI 2016, 2018

Tabel 9. Membuat $1 \mathrm{~m} 3$ Beton Mutu f'c $=21,7 \mathrm{MPa}(\mathrm{K} 250)$, slump (12 \pm 2$) \mathrm{cm}$

\begin{tabular}{|c|l|r|r|r|r|r|}
\hline No & \multicolumn{1}{|c|}{ Uraian } & Kode & Satuan & Koefisien & Harga Satuan (Rp) & Jumlah Harga (Rp) \\
\cline { 1 - 4 } A & Tenaga & & & & & \\
& Pekerja & L.01 & OH & 1.6500 & $77,600.00$ & $128,040.00$ \\
& Tukang Batu & L.02 & OH & 0.2750 & $93,120.00$ & $25,608.00$ \\
& Kepala Tukang & L.03 & OH & 0.0280 & $106,700.00$ & $2,987.60$ \\
& Mandor & L.04 & OH & 0.0830 & $101,850.00$ & $8,453.55$ \\
\hline \multicolumn{7}{|r|}{}
\end{tabular}

Sumber: SNI 2016, 2018

\section{Perhitungan Harga Satuan Upah Berdasarkan Pengamatan Lapangan}

Berdasarkan koefisien tenaga kerja yang telah dihitung sebelumnya, maka berikut ini akan ditampilkan harga satuan pekerjaan berdasarkan pengamatan lapangan.

\section{Pekerjaan Penulangan/Pembesian Kolom 40/40}

Tabel 10. Harga Satuan tenaga kerja di Lapangan Pada Pekerjaan Pembesian Kolom

\begin{tabular}{clcccc}
\hline No & Tenaga Kerja & Koefisien & Satuan & Harga Satuan (Rp) & Jumlah Harga (Rp) \\
\hline 1 & Pekerja & 0,0630 & OH & Rp. 77.600 & Rp. \\
2 & Tukang Besi & 0,0610 & OH & Rp. 93.120 & Rp. $5.680,32$ \\
3 & Mandor & 0,0400 & OH & Rp. 101.850 & Rp. $4.074,00$ \\
Jumlah Upah & & & & Rp. 14.643,12 \\
\hline
\end{tabular}

Sumber: Hasil Perhitungan, 2018

\section{Pekerjaan Bekisting Kolom 40/40}


Elvira Handayani, M. Nuklirullah dan Ahmad Riyadi, Analisa Koefisien Harga Satuan Tenaga Kerja di Lapangan Dengan Analisa SNI Struktur Bangunan Gedung di Kota Jambi

Tabel 11. Harga Satuan tenaga kerja di Lapangan Pada Pekerjaan Bekisting Kolom

\begin{tabular}{clcccc}
\hline No & Tenaga Kerja & Koefisien & Satuan & Harga Satuan (Rp) & Jumlah Harga (Rp) \\
\hline 1 & Pekerja & 0,5200 & OH & Rp. 77.600 & Rp. 40.352,00 \\
2 & Tukang Kayu & 0,0323 & OH & Rp. 93.120 & Rp. $3.007,78$ \\
3 & Mandor & 0,0280 & OH & Rp. 101.850 & Rp. $2.851,80$ \\
Jumlah Upah & & & & Rp. 46.211,58 \\
\hline
\end{tabular}

Sumber: Hasil Perhitungan, 2018

\section{Pekerjaan Pengecoran Kolom 40/40}

Tabel 12. Harga Satuan tenaga kerja di Lapangan Pada Pekerjaan Pengecoran Kolom

\begin{tabular}{cccccc}
\hline No & Tenaga Kerja & Koefisien & Satuan & Harga Satuan (Rp) & Jumlah Harga (Rp) \\
\hline 1 & Tukang Batu & 0,2750 & OH & Rp. 93.120 & Rp $11.081,28$ \\
2 & Mandor & 0,0830 & OH & Rp. 101.850 & Rp. $7.272,09$ \\
Jumlah Upah & & & & Rp $18.353,37$ \\
\hline
\end{tabular}

Sumber: Hasil Perhitungan, 2018

\section{Perhitungan Harga Satuan Upah Berdasarkan Analisa SNI}

Harga satuan pekerjaan berdasarkan SNI akan digunakan sebagai pembanding dengan harga satuan berdasarkan pengamatan lapangan, SNI yang akan digunakan adalah SNI 2016 adalah sebagai berikut:

\section{Pekerjaan Penulangan/Pembesian Kolom 40/40}

Tabel 13. Harga Satuan tenaga kerja berdasarkan SNI Pada Pekerjaan Pembesian Kolom

\begin{tabular}{clcccc}
\hline No & Tenaga Kerja & Koefisien & Satuan & Harga Satuan (Rp) & Jumlah Harga (Rp) \\
\hline 1 & Pekerja & 0,0700 & OH & Rp. 77,600 & Rp. $5.432,00$ \\
2 & Tukang Besi & 0,0700 & OH & Rp. 93.120 & Rp. $6.518,40$ \\
3 & Mandor & 0,0400 & OH & Rp. 101.850 & Rp. $7.129,50$ \\
Jumlah Upah & & & & Rp. $19.079,90$ \\
\hline
\end{tabular}

Sumber: Analisa SNI 2016, 2018

\section{Pekerjaan Bekisting Kolom 40/40}

Tabel 14. Harga Satuan tenaga kerja berdasarkan SNI Pada Pekerjaan Bekisting Kolom

\begin{tabular}{clcccc}
\hline No & Tenaga Kerja & Koefisien & Satuan & Harga Satuan (Rp) & Jumlah Harga (Rp) \\
\hline 1 & Pekerja & 0,6600 & OH & Rp. 77,600 & Rp. 51.216,00 \\
2 & Tukang Besi & 0,3300 & OH & Rp. 93.120 & Rp. 30.729,60 \\
3 & Mandor & 0,0330 & OH & Rp. 101.850 & Rp. $3.361,05$ \\
Jumlah Upah & & & & Rp. 85.306,65 \\
\hline
\end{tabular}

Sumber: Analisa SNI 2016, 2018

Pekerjaan Pengecoran Kolom 40/40

Tabel 15. Harga Satuan tenaga kerja berdasarkan SNI Pada Pekerjaan Pengecoran Kolom

\begin{tabular}{clcccc}
\hline No & Tenaga Kerja & Koefisien & Satuan & Harga Satuan (Rp) & Jumlah Harga (Rp) \\
\hline 1 & Tukang Batu & 0,2750 & OH & Rp. 93.120 & Rp. $25,608,00$ \\
2 & Mandor & 0,0830 & OH & Rp. 101.850 & Rp. $8.453,55$ \\
Jumlah Upah & & & & Rp. 34.061,55 \\
\hline
\end{tabular}

Sumber: Analisa SNI 2016, 2018

\section{Perbandingan Harga Satuan Tenaga Kerja Berdasarkan Pengamatan di Lapangan dengan Metode SNI}

Berdasarkan hasil perhitungan didapatkan perbandingan antara harga satuan tenaga kerja di Lapangan dengan SNI sebagai berikut:

Tabel 16. Perbandingan harga upah satuan pekerjaan berdasarkan pengamatan langsung dan analisa SNI

\begin{tabular}{cllc}
\hline No & \multicolumn{1}{c}{ Item Pekerjaan } & \multicolumn{1}{c}{ Lapangan } & SNI \\
\hline 1 & Pembesian Kolom & Rp. 14.643,12 & Rp. 19.079,90 \\
2 & Bekisting Kolom & Rp. 46.211,58 & Rp. 85.306,65 \\
3 & Pengecoran Kolom & Rp. 18.353,37 & Rp. 34.061,55 \\
\hline Sum
\end{tabular}

Sumber: Hasil Perhitungan, 2018 
Elvira Handayani, M. Nuklirullah dan Ahmad Riyadi, Analisa Koefisien Harga Satuan Tenaga Kerja di Lapangan Dengan Analisa SNI Struktur Bangunan Gedung di Kota Jambi

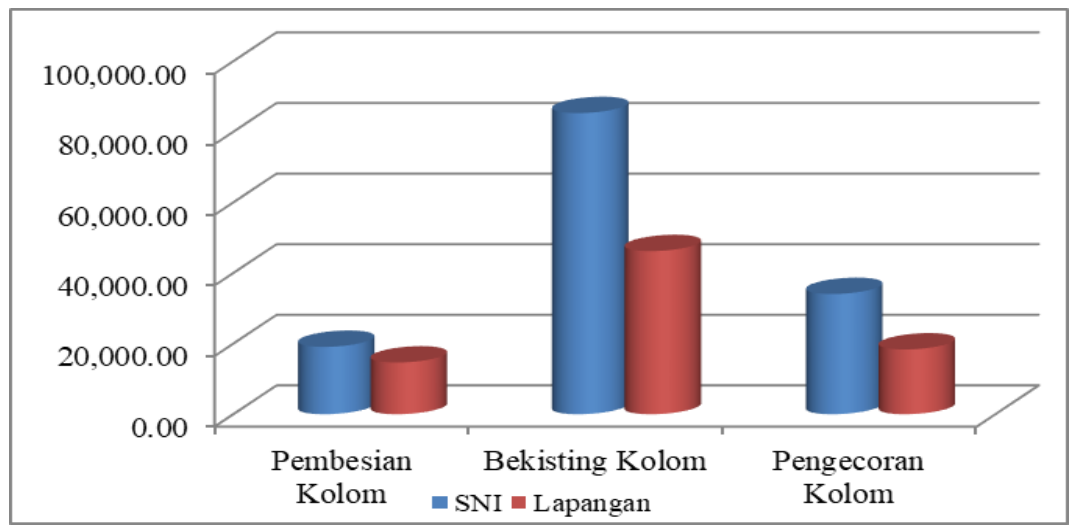

Gambar 2. Grafik Perbandingan Koefisien Upah Tenaga Kerja Berdasarkan Pengamatan Lapangan dan SNI 2016 Sumber: Hasil Analisa, 2018

\section{SIMPULAN}

Berdasarkan pengamatan di lapangan, didapatkan besarnya koefisien harga satuan pekerjaan untuk pekerjaan Kolom ukuran 40x40 cm :

1. Koefisien harga satuan pekerjaan untuk pekerjaan $10 \mathrm{~kg}$ Pembesian adalah 0,0630 Pekerja; 0,0610 Tukang Besi; dan 0,0400 Mandor.

2. Koefisien harga satuan pekerjaan untuk pekerjaan $1 \mathrm{~m} 2$ Bekisting adalah 0,5200 Pekerja; 0,0323 Tukang Kayu; dan 0,0280 Mandor.

3. Koefisien harga satuan pekerjaan untuk pekerjaan $1 \mathrm{~m} 3$ Pengecoran Beton adalah 0,1190 Tukang Batu; dan 0,0714 Mandor.

4. Perbandingan Harga Upah untuk setiap item pekerjaan Kolom 40x40 cm adalah sebagai berikut :

a. Pekerjaan Pembesian Kolom Harga Upah di Lapangan lebih kecil di bandingkan SNI 2016 dengan selisih Rp. $15.708,18$

b. Pekerjaan Bekisting Kolom Harga Upah di Lapangan lebih kecil di bandingkan SNI 2016 dengan selisih Rp. 4.436,78

c. Pekerjaan Pengecoran Kolom Harga Upah di Lapangan lebih kecil di bandingkan SNI 2016 dengan selisih Rp. 39.095,07

\section{DAFTAR PUSTAKA}

Azwar, Syifuddin. 2007. Sikap Manusia Teori dan Pengukurannya. Yogyakarta: Pustaka Pelajar.

Bachtiar, H. Ibrahim. 1993. Rencana dan Estimate Real of Cost. Jakarta: Bumi Aksara.

Barnes, Ralph M. 1973. Motion and Time Study: Design and Measurement of Work. 7th Edition. New York: John Wiley \& Sons Inc.

Dinas Pekerjaan Umun dan Perumahan Rakyat. 2016. Daftar Harga Upah dan Bahan; Daftar Analisa Harga Satuan Pekerjaan. Jambi.

Djojowirono, Sugeng. 1984. Manajemen Konstruksi I. Yogyakarta: Andi.

Husen, Abrar. 2009. Manajemen Proyek Perencanaan Penjadwalan \& Pengendalian Proyek. Yogyakarta: Andi Offset.

Umar. 1998. Riset Sumber Daya Manusia Dalam Organisasi. Jakarta: PT. Gramedia Pustaka Utama.

John W. Niron. 1992. Pedoman Praktis Anggaran dan Borongan Rencana Anggaran Biaya Bangunan. Jakarta: CV. Asona.

Kementerian Pekerjaan Umum. 2016. Pedoman Analisis Harga Satuan Pekerjaan Bidang Pekerjaan Umum. Indonesia.

Kodoatie, Robert J. 2005. Pengantar Manajemen Infrastruktur. Yogyakarta: Pustaka Belajar.

Mukomoko, J. A. 1987. Dasar Penyusunan Anggaran Biaya Bangunan. Jakarta : Gaya Media Pratama

Olomolaiye, P, O., Jayawardane, A, K, W. Harris, F, C. 1998. Construction Productivity Management. England: Longman.

Sastraatmadja, Soedrajat A. 1993. Analisa Anggaran Biaya Pelaksanaan. Bandung: Nova.

Soeharto, I. 1997. Manajemen Proyek Dari Konseptual Sampai Operasional Jilid 1. Jakarta: Erlangga.

Soeharto, I. 1997. Manajemen Proyek Dari Konseptual Sampai Operasional Jilid 2. Jakarta: Erlangga.

Sulistyawan, Abriyani. 2007. Perhitungan Rencana Anggaran Biaya Proyek Konstruksi Dengan Bahasa Pemrograman Visual Basic. Universitas Diponegoro. 